\title{
Temporal and spatial integration for electrocutaneous stimulation
}

\author{
ATSUKI HIGASHIYAMA \\ University of Osaka Prefecture, Osaka, Japan \\ and \\ TAKARA TASHIRO \\ Osaka City University, Osaka, Japan
}

\begin{abstract}
Three experiments investigated the properties of temporal and spatial integration for electrocutaneous stimulation at absolute threshold level. The duration of pulses delivered to the skin were varied from .1 to $100 \mathrm{msec}$, and the spatial distribution of stimulation was varied by controlling separation, width, and length of electrodes. For temporal integration, the threshold currents were fitted by the equation $\left(I-I_{0}\right) \cdot t^{n}=c$, indicating that partial integration took place below the critical duration of $1 \mathrm{msec}$ and that the integration index remained constant ( $n=.43$ ) independent of the spatial distribution of stimulation. For spatial integration, the separation of electrodes was found to be the most effective determiner of threshold current. Furthermore, when the equation $\left(I-I_{0}\right) \cdot A^{m}=\mathbf{k}$ was fitted to the spatial integration data, the value $\mathrm{m}$ resulted in 1.33 with a critical separation of $8 \mathrm{~mm}$, which was constant for any pulse duration.
\end{abstract}

The present study deals with temporal and spatial integration for electrocutaneous stimulation at absolute threshold level. Babkoff, Brandeis, and Bergman (1975), Hahn (1958), Rollman (1969, 1975), and Uttal (1958) showed how threshold varies with pulse duration and obtained the psychophysical hyperbolic function:

$$
\left(I-I_{0}\right) \cdot t^{n}=c,
$$

where $I_{0}$ is the rheobase, $n$ is the temporal integration index, and $\mathrm{c}$ is the constant which depends both on the subject and on the task. The first purpose of this study was to examine the usefulness of Equation 1. A number of studies (Babkoff et al., 1975; Rollman, 1969, 1975) had commonly shown that (1) perfect integration $(n=1)$ occurs at pulse durations of less than $80 \mu \mathrm{sec}$, (2) partial integration $(\mathrm{n}<1$ ) occurs at durations of $80 \mu \mathrm{sec}$ to $10 \mathrm{msec}$, and (3) no integration $(n=0)$ occurs at durations beyond $10 \mathrm{msec}$. It should be noted, however, that those findings were established on the basis of one type of electrode which was arbitrarily constructed for a particular purpose. In order to generalize the

We are grateful to Dr. Jiro Kawamura of the Osaka Rosai Hospital and Dr. Kazuyosini Nishihara of the Osaka Electrocommunication University, who served as advisors on this project. A. Higashiyama's mailing address is: Psychology Laboratory, University of Osaka Prefecture, Mozu-umemachi, Sakai, Osaka 591, Japan. T. Tashiro's mailing address is: Department of Psychology, Osaka City University, Sumiyoshi-ku, Osaka 558, Japan. properties of temporal integration, therefore, it was necessary to confirm the previous findings by using different types of electrodes.

In the studies of vision, touch, and hearing, the equation

$$
\left(I-I_{0}\right) \cdot A^{m}=k
$$

was used to show how threshold intensity I depends on spatial variable $A$. The constant $I_{0}$ is a correction factor, and $\mathrm{m}$ is a spatial integration index. According to conventional analyses, the spatial variable that arouses sensory experiences has been assumed to be stimulus size, that is, stimulus area for both vision and touch and stimulus frequency for hearing (Marks, 1978).

Compared with the data for other sense modalities, the data on spatial integration for electrocutaneous stimulation are not very numerous. To our knowledge, the only study previous to our own is that of $\mathbf{R}$. $\mathbf{H}$. Gibson (1968), who examined the effects of electrode area for circular electrodes and found threshold current to increase with increasing electrode area. However, spatial variables for electrocutaneous stimulation are somewhat more complex than are those for other sense modalities. Let us consider bipolar rectangle electrodes, which are illustrated in Figure 1. In that case, the electrodes can be described in terms of the three simple variables: separation, length, and width. Separation (S) is defined as lateral separation between the inner edges of the electrodes; length $(\mathrm{L})$ is defined as the electrode side parallel to the current- 


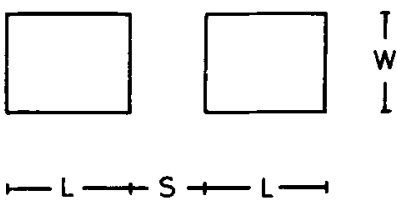

Figure 1. Three simple spatial variables of bipolar rectangle electrodes: S, separation; $W$, width; and $L$, length. The combinations of the simple variables produce contact area (2WL) and current-running area [W(2L+S)] which are higher order complex variables.

running direction; and width (W) is defined as the electrode side perpendicular to the current direction. In addition to those simple variables, there seem to be two complex variables that can be constructed by combining the following variables: contact area, defined as $2 \mathrm{LW}$, and current-running area, represented by W $(2 L+S){ }^{1}$

The second purpose of this study, therefore, was to find what major spatial variables contributed to electrocutaneous sensitivity and to test whether Equation 2 could be adequately fitted to the data on spatial integration.

In three experiments reported here, electrical stimuli were single short pulses varying in duration and spatial variables. Eight durations of .1 to $100 \mathrm{msec}$ were used for any pair of electrodes. The five simple and complex variables mentioned above were systematically changed: In Experiment 1, separation and current-running area were varied and the other three variables were held constant; in Experiment 2, all variables except for separation and length were varied; in Experiment 3, separation, length, and contact area were varied and the other variables were held constant. The spatial characteristics of the electrodes used in this study are summarized in Table 1. Table 1 helps to predict the major spatial variables determining threshold current. For example, if threshold current varies with spatial variables in Experiments 1 and 3, separation may be an important determiner of threshold current. Similarly, if it does so in Experiments 1 and 2, the changes of threshold current may be conceived to

Table 1

Simple and Complex Variables of Electrodes Used in Experiments 1-3

\begin{tabular}{|c|c|c|c|}
\hline \multirow{2}{*}{$\begin{array}{l}\text { Spatial } \\
\text { Variable }\end{array}$} & \multicolumn{3}{|c|}{ Experiment } \\
\hline & 1 & 2 & 3 \\
\hline \multicolumn{4}{|c|}{ Simple Variable } \\
\hline $\begin{array}{l}\text { Separation } \\
\text { Width } \\
\text { Length }\end{array}$ & $\begin{array}{l}\text { Variable } \\
\text { Constant } \\
\text { Constant }\end{array}$ & $\begin{array}{l}\text { Constant } \\
\text { Variable } \\
\text { Constant }\end{array}$ & $\begin{array}{l}\text { Variable } \\
\text { Constant } \\
\text { Variable }\end{array}$ \\
\hline \multicolumn{4}{|c|}{ Complex Variable } \\
\hline $\begin{array}{l}\text { Contact Area } \\
\text { Current-Running Area }\end{array}$ & $\begin{array}{l}\text { Constant } \\
\text { Variable }\end{array}$ & $\begin{array}{l}\text { Variable } \\
\text { Variable }\end{array}$ & $\begin{array}{l}\text { Variable } \\
\text { Constant }\end{array}$ \\
\hline
\end{tabular}

result from changes in the current-running area. In any event, the crucial variables for electrocutaneous stimulation can be identified on the basis of patterns resulting from the three experiments.

\section{METHOD}

\section{Apparatus}

The apparatus was the same as that used in Tashiro and Higashiyama (1981). A constant-current stimulator was used: a de power supply (Kikusui Electronics Model PAF), operated at $400 \mathrm{~V}$, was connected to resistors ranging from .5 to $67 \mathrm{M} \Omega$, accurate to within $1 \%$. Pulse duration and the timing of a trial were controlled by combining a Sanwa time regulator and a Sanwa noncontact relay circuit. Pulse shape and duration were calibrated using a Takeda-Riken Type TR5151 electronics counter in series with a Hitachi Type V-302 oscilloscope. The current delivered to the skin was estimated by a Sanwa Electric Instrument Model 9000EA digital ammeter.

\section{Stimulus Conditions}

Sixteen pairs of bipolar silver electrodes were used. Each pair of electrodes was fitted into a plastic plate that was strapped over the underside of the right wrist in the vicinity of ulnar nerve.

In Experiment 1, five pairs of electrodes were used. These were squares with $7-\mathrm{mm}$ sides and with inner edges that were separated laterally by a distance of $2,4,8,16$, or $32 \mathrm{~mm}$. Thus, the current-running area varied from 112 to $322 \mathrm{~mm}^{2}$, while the contact area was constant at $49 \mathrm{~mm}^{2}$ for any pair of electrodes.

In Experiment 2, six pairs of electrodes were used. These were $7 \mathrm{~mm}$ in length, $4 \mathrm{~mm}$ in separation, and $1,2,3,5,7$, or $10 \mathrm{~mm}$ in width. Consequently, the current-running area varied from 18 to $180 \mathrm{~mm}^{2}$ and the contact area varied from 14 to $140 \mathrm{~mm}^{2}$.

In Experiment 3, five pairs of electrodes were constructed so as to keep width at $7 \mathrm{~mm}$ : five separations of $3,4,8,16$, and $20 \mathrm{~mm}$ were paired with five lengths of $9.5,8,7,3$, and $2 \mathrm{~mm}$, respectively. This arrangement varied contact area from 28 to $133 \mathrm{~mm}^{2}$ and kept current-running area at $168 \mathrm{~mm}^{2}$.

In all experiments, eight different pulse durations were used for each pair of electrodes: $.1, .3, .6,1,3,10,30$, and 100 msec. Thus, when pulse durations were combined with the spatial variables of the electrodes, Experiments 1 and 3 each produced 40 $(5 \times 8)$ stimulus conditions and Experiment 2 yielded $48(6 \times 8)$ stimulus conditions.

\section{Procedure}

The subject was seated, with his right hand resting on the table. Prior to attachment of the electrodes, the subject's wrist was washed with an alcohol solution. The electrodes were then filled with Keratin electrode paste and applied to the underside of the wrist so as to locate the cathode electrode close to the palm.

An absolute threshold was determined by a staircase procedure for each stimulus condition. Each subject was required to make at least 32 yes-no judgments for each stimulus condition. Each trial was started with the lighting of a red warning lamp, which was followed, after a delay of $2 \mathrm{sec}$, by a pulse to the electrodes. A stimulus was presented on every trial; no blank trials were used. Intertrial intervals were approximately $10 \mathrm{sec}$.

An experiment consisted of five or six sessions. In each session, eight thresholds were obtained from each subject for a given pair of electrodes. The presentation order of duration and electrodes was determined differently for each subject. It took approximately $80 \mathrm{~min}$ to complete one session.

\section{Subjects}

The subjects were eight male students (Ha, ME, MT, Ya, Ta, $\mathrm{Ku}, \mathrm{Na}$, and $\mathrm{TN}$ ), who were enrolled in the course of human 
sciences at the University of Osaka Prefecture. Five (Ha, ME, $\mathrm{MT}, \mathrm{Ya}$, and $\mathrm{Ta}$ ) of them served in Experiment 1, five $(\mathrm{Ha}$, $\mathrm{ME}, \mathrm{MT}, \mathrm{Ya}$, and $\mathrm{Ku}$ ) served in Experiment 2, and four ( $\mathrm{Ha}$, $\mathrm{ME}, \mathrm{TN}$, and $\mathrm{Na}$ ) served in Experiment 3. They were all paid for their participation.

\section{RESULTS AND DISCUSSION}

On the basis of the computational manual of Dixon and Massey (1957, chap. 19), an absolute threshold was determined individually for each combination of duration and electrodes. A two-way analysis of variance for repeated measures was then performed on the threshold data obtained from each experiment. In Experiment 1, two main effects were significant [for duration, $F(7,28)=12.20$, $p<.001$, and for separation, $F(4,16)=5.33, p<$ $.01]$, but the interaction was not significant. In Experiment 2, the main effect for duration was significant $[F(7,28)=124.51, p<.001]$, but the main effect for width and its interaction with duration were not significant. In Experiment 3, there were significant main effects for duration $[F(7,21)=$ $224.09, p<.001]$ and for the separation-length combination $[F(4,12)=14.43, p<.001]$, but the interaction was not significant. Those results led to the conclusion that duration of pulse and separation of electrodes are the most crucial variables and that other simple and complex spatial variables are not relevant to electrocutaneous sensitivity.

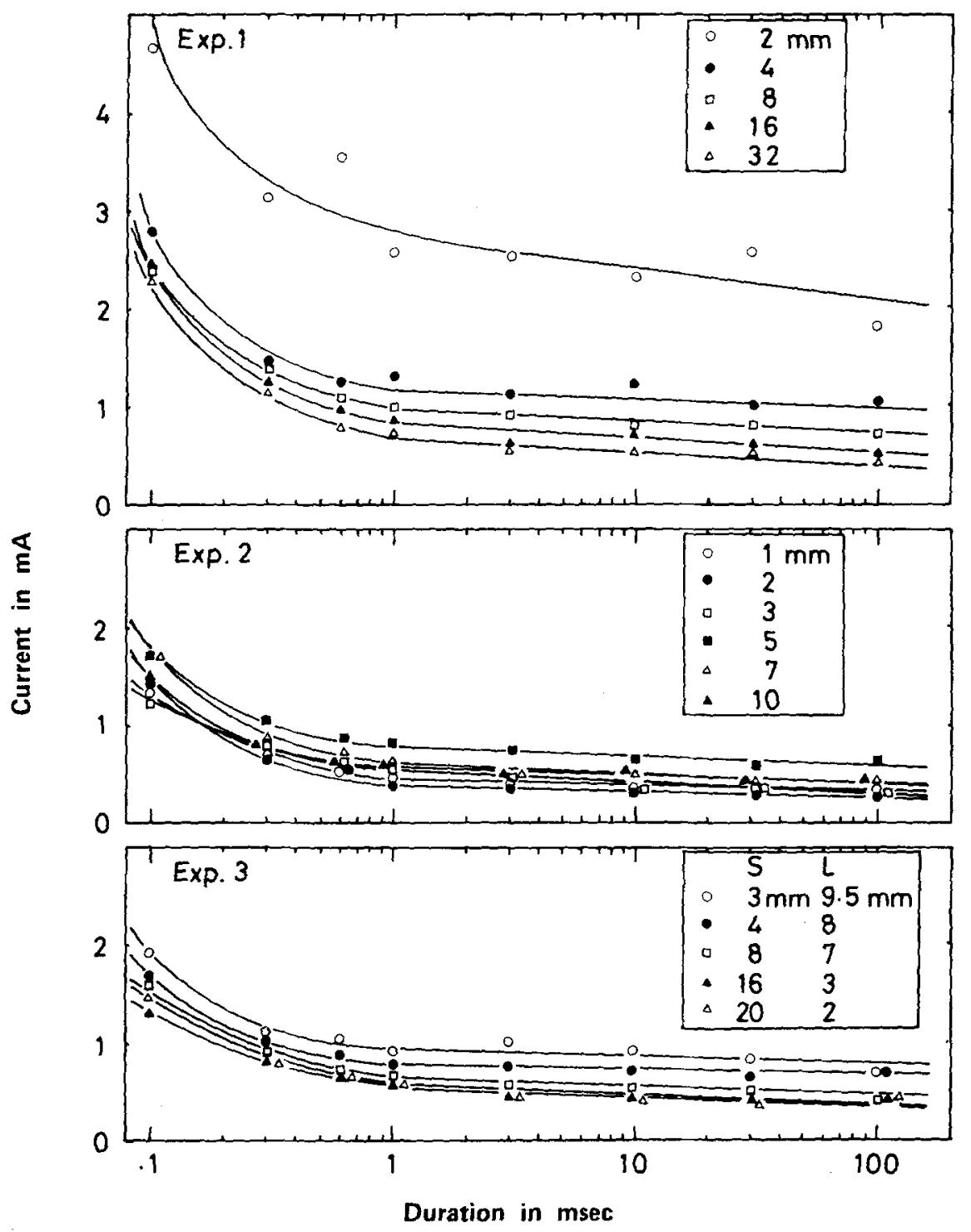

Figure 2. Temponl integration functions obtained in Experiments 1 to 3. Mean threshold current in microsmps plotted on the ordingte as a function of pulse duration in milliseconds on logalismic abscisas. The parameters, from top to bottom, are separation, width, and the separation-length combination. 


\section{Temporal Integration}

The results of Experiments 1-3 are shown in Figure 2 , in which threshold current is represented as a function of duration. Each data point is based on a mean of the current thresholds of the subjects employed. The parameters of the top, middle, and bottom parts of Figure 2 are separation, width, and the separation-length combination of electrodes, respectively. To clarify the relation between threshold current and pulse duration, Equation 1 was fitted to the threshold data for each pair of electrodes. Since Equation 1 can be transformed into $\log \left(I-I_{0}\right)$ $=-n \log t+\log c, \log \left(I-I_{0}\right)$ would be a linear function of $\log t$. A computer was used to determine the best-fitting function for each pair of electrodes so as to produce the maximal coefficient of determination $\left(r^{2}\right)$ between $\log t$ and $\log \left(I-I_{0}\right)$. Table 2 shows the parametric characteristics of the bestfitting functions: $n, I_{0}, \log c$, and $r^{2}$.

Figure 2 revealed that the critical duration of temporal integration, which is usually defined as an abrupt transition between integration and no integration, was 1 or $.6 \mathrm{msec}$, beyond which temporal integration does not occur. This finding confirms previous studies (Rollman, 1969, 1975). Moreover, as is evident from Table 2, integration indexes of $\mathrm{n}$ are generally larger than zero and smaller than unity. This implies the occurrence of partial integration. The overall mean and standard deviation of the $n$ values in Table 2 are .432 and .099 , respectively. This finding can be related to the studies of

Table 2

Simple Spatial Variables (in Millimeters) of Electrodes Used in Experiments 1-3 and Parameters of Hyperbolic Functions Fitted to the Intensity-Duration Relation at Absolute Threshold Level

\begin{tabular}{|c|c|c|c|c|c|c|}
\hline \multicolumn{3}{|c|}{ Simple Variable } & \multicolumn{4}{|c|}{ Hyperbolic Function } \\
\hline $\mathrm{S}$ & Width & Length & $\mathrm{n}$ & $I_{0}$ & $\log c$ & $\mathrm{r}^{2}$ \\
\hline \multicolumn{7}{|c|}{ Experiment 1} \\
\hline $\begin{array}{r}2 \\
4 \\
8 \\
16 \\
32\end{array}$ & $\begin{array}{l}7 \\
7 \\
7 \\
7 \\
7\end{array}$ & $\begin{array}{l}7 \\
7 \\
7 \\
7 \\
7\end{array}$ & $\begin{array}{l}.209 \\
.349 \\
.471 \\
.526 \\
.476\end{array}$ & $\begin{array}{r}1.26 \\
.94 \\
.69 \\
.52 \\
.42\end{array}$ & $\begin{array}{r}.239 \\
-.390 \\
-.381 \\
-.376 \\
-.356\end{array}$ & $\begin{array}{l}.816 \\
.809 \\
.940 \\
.925 \\
.925\end{array}$ \\
\hline \multicolumn{7}{|c|}{ Experiment 2} \\
\hline $\begin{array}{l}4 \\
4 \\
4 \\
4 \\
4 \\
4\end{array}$ & $\begin{array}{r}1 \\
2 \\
3 \\
5 \\
7 \\
10\end{array}$ & $\begin{array}{l}7 \\
7 \\
7 \\
7 \\
7 \\
7\end{array}$ & $\begin{array}{l}.510 \\
.503 \\
.288 \\
.390 \\
.612 \\
.448\end{array}$ & $\begin{array}{l}.30 \\
.24 \\
.19 \\
.54 \\
.43 \\
.41\end{array}$ & $\begin{array}{l}-.638 \\
-.597 \\
-.405 \\
-.473 \\
-.675 \\
-.612\end{array}$ & $\begin{array}{l}.963 \\
.938 \\
.896 \\
.893 \\
.947 \\
.864\end{array}$ \\
\hline \multicolumn{7}{|c|}{ Experiment 3} \\
\hline $\begin{array}{r}3 \\
4 \\
8 \\
16 \\
20\end{array}$ & $\begin{array}{l}7 \\
7 \\
7 \\
7 \\
7\end{array}$ & $\begin{array}{l}9.5 \\
8 \\
7 \\
3 \\
2\end{array}$ & $\begin{array}{l}.299 \\
.389 \\
.415 \\
.504 \\
.471\end{array}$ & $\begin{array}{l}.61 \\
.61 \\
.39 \\
.40 \\
.40\end{array}$ & $\begin{array}{l}-.356 \\
-.585 \\
-.467 \\
-.659 \\
-.658\end{array}$ & $\begin{array}{l}.812 \\
.829 \\
.931 \\
.956 \\
.845\end{array}$ \\
\hline
\end{tabular}

Note-S = separation .
Babkoff (1978) and Babkoff et al. (1975). In particular, Babkoff et al., who fitted a simple hyperbolic function, $I \cdot t^{\text {n }}=c$, to the temporal integration data for single pulses ranging from 175 to $610 \mu \mathrm{sec}$, obtained an $n$ value of .52 for one subject and .64 for the other. In addition, Babkoff et al. estimated $n=.55$ on the basis of the data presented by Rollman (1975) for durations extending from $80 \mu \mathrm{sec}$ to $1 \mathrm{msec}$. It seems that there is no substantial difference between the $n$ values analyzed by Babkoff et al. and those of the present study, despite the use of different electrodes, stimulus ranges, and scaling procedure.

The generally higher thresholds obtained in Experiment 1 than in the other experiments (see top part of Figure 2) were due to the extremely high thresholds of Subjects Ta and MT, rather than to the particular spatial configuration of the electrodes used. In fact, the thresholds of these two subjects were two or three times as large as the corresponding thresholds of the other subjects serving in Experiment 1. In Experiment 2, however, the extremely high thresholds of the two subjects disappeared and became compatible with those of the other subjects. This change of threshold data can be accounted for in terms of perceptual learning inasmuch as perceptual skills are improved with practice. E. J. Gibson (1969), for example, pointed out that perceptual learning occurs even in such a simple task as detection and leads to reduced threshold with practice.

\section{Spatial Integration}

By analogy with temporal integration, threshold data were analyzed in terms of spatial integration. In Figure 3, the threshold data obtained in Experiments 1 and 3 is replotted against separation of electrodes with duration as parameter. Needless to say, the results of Experiment 2 could not be analyzed, because the electrodes used were varied in width but constant in separation and length. Equation 2 was then fitted to the data of Figure 3 in a way similar to that of temporal integration. The results thus computed are summarized in Table 3.

Figure 3 and Table 3 provide two new findings: (1) An increase in separation above $8 \mathrm{~mm}$ brings about little change in threshold current. Below $8 \mathrm{~mm}$, however, a change in current intensity can be offset by a change in separation in order to preserve the absolute threshold level. (2) As suggested in Table 3, when Equation 2 was fitted to the threshold data, it produced more stable $\mathrm{m}$ values with higher coefficients of determination for the data of Experiment 1 than for the data of Experiment 3. This discrepancy was probably due to the difference of separation ranges used in Experiments 1 and 3. As the range of an independent variable decreases, the correlation between the independent variable and the 


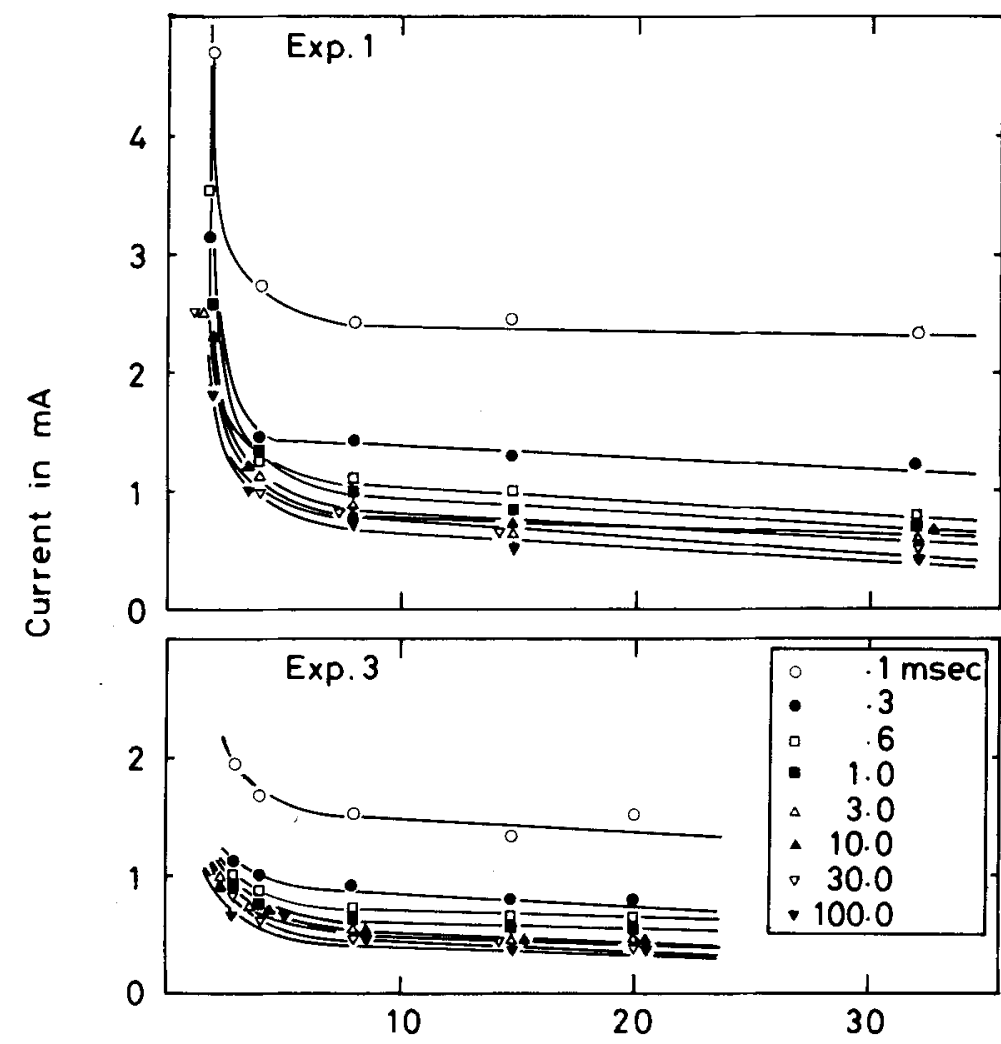

Separation in $\mathrm{mm}$

Figure 3. Spatial integration functions obtained in Experiments 1 and 3. Mean threshold current in microamps plotted on the ordinate as a function of separation in millimeters on the abscissa. The parameter is pulse duration.

corresponding dependent variable tends to become lower, because random fluctuations of the dependent variable are expected to greatly contribute to the coefficient of correlation. Values of $m$ obtained in Experiment 1, therefore, may be more reliable than those obtained in Experiment 3. If this explanation is acceptable, it can be concluded from Table 3 that Equation 2 can be adequately fitted to spatial integration data and that the resulting $m$ values are generally larger than unity (on the average, $\mathrm{m}=1.325, \mathrm{SD}=.197$ ).
One might ask why the spatial integration index $m$ is larger than unity, a situation rarely found in other sense modalities. There are two possible interpretations for the abrupt increases of threshold current for the electrodes with a narrow separation. One is that the cream patches under the two electrodes may come into contact with each other and create a local short circuit. Accordingly, true threshold current would be obtained by subtracting the current flowing through the short circuit from the threshold current measured in Experiments 1 to 3 .

Table 3

Parameters of Hyperbolic Functions Fitted to the Intensity-Separation Relation at Absolute Threshold Level

\begin{tabular}{|c|c|c|c|c|c|c|c|c|}
\hline \multirow{2}{*}{$\begin{array}{l}\text { Duration (in } \\
\text { Milliseconds) }\end{array}$} & \multicolumn{4}{|c|}{ Experiment 1} & \multicolumn{4}{|c|}{ Experiment 3} \\
\hline & $\mathrm{m}$ & $I_{0}$ & $\log k$ & $\mathrm{r}^{2}$ & $\mathrm{~m}$ & $I_{0}$ & $\log k$ & $\mathrm{r}^{2}$ \\
\hline .1 & 1.536 & 2.31 & .607 & .902 & .147 & .0 & .333 & .791 \\
\hline .3 & 1.484 & 1.21 & .585 & .944 & .173 & .0 & .121 & .988 \\
\hline .6 & 1.213 & .73 & .691 & .923 & 1.310 & .64 & .166 & .956 \\
\hline 1.0 & 1.121 & .68 & .561 & .984 & .722 & .48 & -.073 & .971 \\
\hline 3.0 & 1.569 & .61 & .730 & .955 & 1.439 & .44 & .409 & .990 \\
\hline 10.0 & 1.426 & .62 & .646 & .995 & 1.049 & .39 & .182 & .978 \\
\hline 30.0 & 1.261 & .48 & .622 & .978 & 1.192 & .39 & .186 & .993 \\
\hline 100.0 & .988 & .37 & .441 & .999 & .265 & .0 & -.042 & .759 \\
\hline
\end{tabular}


The other interpretation is based on the two assumptions: first, that threshold current is determined by the total effective area's varying as a function of electrode separation (the total effective area implies an actual area activated by delivering current to the skin); and second, that the total effective area increases with a positive acceleration as a function of electrode separation. Given those assumptions, it follows that a change in electrode separation requires a greater change in total effective area. For example, a twofold increase in electrode separation produces a more-than-twofold increase in total effective area; inversely, a half decrease in electrode separation yields a less-than-half decrease in total effective area. Thus, when threshold current is plotted as a function of total effective area, the resulting intensity-area curves would produce lower values of $m$ than those shown in Table 3. Both interpretations predict perfect spatial integration for electrocutaneous stimulation, but it is difficult to rule out either interpretation on the basis of the present results.

Another important finding of this study is that the critical duration and $n$ values of temporal integration do not seem to change systematically with the spatial variables of electrodes. This implies that temporal integration is independent of how current is distributed in the cutaneous surface during an integration interval. This is in notable contrast to brightness perception. Barlow (1958) and Graham and Margaria (1935), for example, found that temporal integration has a longer duration when the stimulus area is small than when it is large. In other words, the critical duration of temporal integration increases with decreasing stimulus area. The inverse relation between critical duration and stimulus area usually has been considered as the funneling of energy from different receptors to a common neuron (e.g., Barlow, 1958). Thus, for a small stimulus area, it takes a long time to fire a common neuron, whereas, for a large stimulus area, the funneling of energy is achieved quickly. The fact that temporal integration is independent of spatial integration for electrocutaneous sensation implies no energycollecting mechanism similar to that of the visual brightness system.

Finally, there is physiological evidence that relates to psychophysical data of electrocutaneous stimulation. Heckmann (1972) and Rollman (1975) pointed out that the psychophysical finding of temporal integration at absolute threshold level resembles the responses of nerve action potential for A fibers. Hallin and Torebjörk (1973), using microelectrodes inserted into nerve fascicles, found that current near absolute threshold produces impulses of short latency which result from large A fibers with rapid conduction velocity. Thus, the above findings may be the reflections of neural activity of $\mathbf{A}$ fibers.

\section{REFERENCES}

BABкоFF, H. Electrocutaneous psychophysical input-output functions and temporal integration. Perception \& Psychophysics, 1978, 23, 251-257.

Babkoff, H., Brandeis, B., \& Bergman, Y. Partial integration of single electrocutaneous pulses. Perception \& Psychophysics, 1975, 17, 285-292.

Barlow, H. B. Temporal and spatial summation in human vision at different background intensities. Journal of Physiology, 1958, 141, 337-350.

DiXon, W. J., \& MASSEY, F. J. Introduction to statistical analysis. New York: McGraw-Hill, 1957.

Gibson, E. J. Principles of perceptual learning. New York: Appleton-Century-Crofts, 1969.

Gibson, R. H. Electrical stimulation of pain and touch. In D. R. Kenshalo (Ed.), The skin senses. Springfield, Ill: Thomas, 1968.

Graham, C. H., \& Margaria, R. Area and the intensity-time in the peripheral retina. American Journal of Physiology, 1935, 113, 299-305.

Hahn, J. F. Cutaneous vibratory thresholds for square-wave electrical pulses. Science, 1958, 127, 879-880.

Hallin, R. G., \& Torebjörk, H. E. Electrically induced A \& $\mathrm{C}$ fibre responses in intact human skin nerves. Experimental Brain Research, 1973, 16, 309-320.

Heckmann, J. R. Excitability curve: A new technique for assessing human peripheral nerve excitability in vivo. Neurology, 1972, 22, 224-230.

Marks, L. E. The unity of the senses. New York: Academic Press, 1978.

Rollman, G. B. Electrocutaneous stimulation: Psychometric function and temporal integration. Perception \& Psychophysics, $1969,5,289-293$.

Rollman, G. B. Behavioral assessment of peripheral nerve function. Neurology, 1975, 25, 339-342.

Tashino, T., \& Higashiyama, A. The properties of electrocutaneous stimulation: Sensory quality, subjective intensity, and intensity-duration relation. Perception \& Psychophysics, 1981, 30, 579-586.

UTTAL, W. R. Cutaneous sensitivity to electrical pulse stimuli. Journal of Comparative and Physiological Psychology, 1958, $51,549-554$.

\section{NOTE}

1. As a matter of fact, it is very difficult to determine how current flows on the skin. If an electrical potential difference occurs between two points that are separated by a homogeneous conduction substance, for example, iron or copper, then the current flows like the magnetic lines of force formed between the north and south poles. However, the human skin consists of layers of complex substances which differ in electrical conductivity. Thus, the concept of a current-running area as defined in the present paper is operational.

(Manuscript received August 16, 1982; revision accepted for publication December 27, 1982.) 